\title{
On Teaching Vocabulary to Non-English Majors
}

\author{
Mai Zhou \\ Foreign Languages School, Zhejiang Gongshang University, Hangzhou, China \\ Email: zhoumai6993@163.com
}

\begin{abstract}
Taking vocabulary problem as the colossal problem for Non-English Majors into consideration, this article makes analysis of the main factors for the problem: the negligence by both the teachers and the students, the alphabetical arrangement of words in the Syllabus simply with Chinese meanings and outdated teaching materials which do not contain sufficient words appearing everyday with the development of the world. The author of the article also attempts to provide a strategy to solve the problem. It includes: use of context, use of morphological clues, use of outside references and extensive reading.
\end{abstract}

Index Terms - vocabulary teaching, vocabulary problems, teaching strategy, non-English majors

\section{VocABUlary AS THE COLOSSAL PROBLEM}

My students are non-English majors coming from different parts of the country. All have developed their English language skills during the first two years of university study under formal instruction, and many of them have themselves made further improvement as well especially in reading during the last two years of university. Now as postgraduates, they will finish their English course: Comprehensive English and Listening Comprehension -in a year that falls into two semesters: in the first semester, they study Reader's Choice; in the second semester, Intensive Multidimensional Course: Approaching Proficiency, Both are authentic materials. The listening material is Focus Listening 6. Each week, they have four hours of Comprehensive English and one hour of Listening Comprehension. The ultimate goal of the reading materials is "to produce independent readers who are able to determine their own goals for a reading task, then use the appropriate skills and strategies to reach those goals, ("Introduction" of Reader's Choice, 2002). The students have high motivation in learning English. In postgraduate stage, grammar rules can no longer be their obstacle, in reading, although they may commit errors in speaking and writing.

During the teaching, I heard from time to time students complain in puzzlement: "I've studied English for more than ten years but I don't seem to have made noticeable progress in English. I can only use more or less the same words as I used before in speaking and writing. "I know all the reading skills and grammar but still I can't understand the exact meaning of this passage." "I recite fifteen words a day. It does help in reading comprehension. But I always forget the words I recited a week ago." The above is not a problem to one or two students but to the majority of them-the problem of vocabulary.

The major problem in reading during the postgraduate stage is vocabulary as, "word meaning knowledge influence reading comprehension" (Harris \& Sipay, 1990).

\section{MAIN FACTORS FOR THE VOCABULARY PROBLEM}

Some factors account for the vocabulary problem. For many years vocabulary was the poor relation of language teaching. Its neglect has been in part due to a specialization in linguistic research on syntax and phonology which may have fostered a climate in which vocabulary was felt to be a less important element in learning a second language. The following statement by Gleason, while strangely appearing to suggest that vocabulary does not have 'content' or 'expression', typifies attitudes held by not a few teachers:

In learning a second language, you will find that vocabulary is comparatively easy, in spite of the fact that it is vocabulary that students fear most. The harder part is mastering new structures in both content and expression. (Gleason, 1961:7 from Ronald Carter,1998:84)

I once did a survey on students' feelings on vocabulary learning at postgraduate stage. Two thirds of them said they were not taught enough words in class, words they needed when talking to people, watching TV, and reading. They felt their teachers were very keen on teaching them grammar (since middle school years) and on improving their pronunciation, but that learning words came a poor third.

Encountering and understanding a word are seldom enough: as with meeting people, there needs to be depth and interaction for the encounter to be memorable. Some teachers do not recognize or neglect such a need. They take it for granted that postgraduate students should be able to develop their own learning systems, and thus put the vocabulary at the disposal of students' memory capacity. Some teachers suggest that students should go home every evening and learn a list of fifty words 'by heart'. Such a practice may have beneficial result, of course, but it avoids one of the central features of vocabulary use, namely that words occur in context.

In the Syllabus, words are listed alphabetically with the correspondent Chinese meaning. Students are required to master all these words that teachers teach them. The main purpose of learning words in the Syllabus or from other 
source (by heart) is to pass the national proficiency tests College English Test Band 4, or Band 6; or to score higher in TOEFL or GRE tests. Many words recited appear only once especially in GRE test after which they will not be used again by students. Therefore, many words are only stored in students' short-term memory as passive words and will never become active ones. The kind of vocabulary learning does not have much long-term effect.

Another factor that leads to the vocabulary problem involves the teaching materials used. Most materials applied nationally have been used for decades. The out-of-date materials obviously do not contain words appearing everyday with the development of the world. Learners, thus, do not have the chance to absorb new words they urgently need to gain access to the new world and the new age. Many materials haven't become authentic only until recently. Authentic materials are an integral part in vocabulary learning since they 'provide valuable opportunities to teach new vocabulary and to practice approaches to vocabulary building'(Silberstein. 1994: 106).

\section{A StRategy to Solve the Vocabulary Problem}

A well-planned, systematic and continuous program is required for vocabulary instruction to be effective, Such a program should include concept development, generating and sustaining an interest in words and a desire to increase one's vocabulary, direct teaching of word meanings, helping pupils learn how to determine word meanings on their own, and providing frequent opportunities for reading (Harris \& Sipay,1990: 516). Teachers can help students build and develop their vocabulary by giving direct instruction and self-help techniques. Direct attention to vocabulary should supplement vocabulary growth through reading. Research strongly suggests that planned or/ and direct instruction is superior to a casual or incidental approach. Planned instruction can be built right into the regular course work and can yield returns in learning subject matter.

\section{A. Use of Context Clues}

There is an important distinction between deriving the meaning of an unfamiliar word from context and learning the meaning of that word. "The strength of learning word meaning from context lies in its long-term cumulative effects." (Harris \& Sipay, 1990:524)

The ability to determine the meaning of vocabulary items from context is one of the most important aspects of successful reading. When bringing reading passages into the classroom, instructors can introduce new vocabulary through use of teacher-developed vocabulary item from context formats.

These activities are valuable in two respects. First, practice inferring meaning from context teaches an important skill. Second, the additional contexts introduced by the teacher will provide semantic links that aid readers in remembering vocabulary items.

Successful vocabulary from context items provide adequate context to suggest meaning without providing a formal definition. It is generally sufficient for students to gain a general sense of an item without its specific parameters.

It is clear that the more advanced the learner becomes, the more 'inferential' or 'implicit' and learner-centered vocabulary learning strategies will have to become. One method, with particular reference to reading, has been proposed by Nation (1988: 89). It involves the learner in seeking clues to meaning by following a number of defined steps which lead from the form of the word itself, to its immediate context, and then to its operation in the surrounding context. In his New Ways in Teaching Vocabulary (1994), Nation claims that "Guessing from context is the most important of the strategies, it is the way native speakers most often expand their vocabulary." (1994:173) The skill of guessing and of using contextual clues to make inferences is important, especially in reading in a foreign language and especially if the learner is to become more self-reliant.

\section{B. Use of Morphological Clues}

Knowledge of frequently recurring (roots, prefixes, suffixes, infixes), when used in conjunction with context clues, can give students another important self-help technique to unlock the meanings of words.

Students can be taught Greek and Latin stems and affixes that supply clues to meaning, When we give students a working stock of common Greek and Latin word parts and teach them to use these in combination with context revelation, we are helping them acquire meanings of many related English words. And we are giving many of them a self-help technique through structural analysis - an added means of increasing their word power in an ongoing, lifelong process.

\section{Use of Outside References}

Students often benefit from instruction and practice using a monolingual English dictionary, "Advanced students can (and should) use their monolingual dictionaries as their chief source of information about meaning, pronunciation and grammar. There is no better resource for the learner." (Harmer, 1991:175) The elements of a dictionary entry should be introduced before students are asked to use dictionaries independently.

Vocabulary items that are used in an unfamiliar way are good candidates for dictionary practice. Students can learn a new word while practicing finding the appropriate definition in an English-English dictionary.

Glossing is a technique available when bringing passages into the classroom that contain difficult vocabulary that is frankly not worth teaching. A short definition is provided, usually in the form of a footnote or marginal note, or provided orally by the teacher. Low-frequency item that students are not likely to encounter again but that will impede 
comprehension can be appropriately glossed. This technique can facilitate bringing authentic, unedited texts such as magazine articles, into the classroom. Before glossing, however, it is important to determine that the item really will impede comprehension. If not, students can be encouraged to sustain the ambiguity of authentic reading.

\section{Extensive Reading}

Wide reading accounts for much of the vocabulary growth of competent readers. Through reading they spend countless hours in a world of words. They meet new words repeatedly in similar and different settings, often with some increment of meaning at each encounter, and gradually incorporate them into their vocabularies. All teachers can encourage students to read widely and to approach their reading with a conscious effort to notice unfamiliar words and to make selected ones their own.

Vocabulary learning does occur in the absence of instruction, and this growth is impressive. When compared with almost any instructional approach, incidental learning of vocabulary appears to be ineffective in the short run, but even a moderate amount of regular feeding is beneficial. Research suggests that vocabulary growth through wide reading is cumulative and especially noted in terms of its long-term effect.

Wide reading not only increases word-meaning knowledge but can also produce gains in topical and world knowledge that can further facilitate reading. Wide reading also broadens the base of words that students can use in employing morphological cues, thus making their use even more effective. By providing extensive practice, wide reading can lead to the automatization of enabling skills (e.g. rapid word recognition and lexical access) that also may improve reading comprehension. Therefore, extensive reading should be encouraged (Harris \& Sipay, 1990:533).

\section{LIMITATIONS OF THE STRATEGY}

The implementation of the plan is likely to encounter some difficulties. For example, context sometimes has nothing at all to a reveal concerning a word's meaning and may on occasion, even mislead the reader (e.g. the word 'noisome'). So context is a magnificent help—-but be aware.

There exist limitations in using word parts. There are deceptive combinations of letters-foolers-which resemble a Greek or Latin word element but are completely unrelated, (e. g. there's nothing necessarily bad about 'a mallet', 'a mallard duck', although the Latin word part, mal-, means bad, wrong or evil. ) Therefore, word parts do not always help. Besides, English has many suffixes, but the majority of them have more than one meaning, so teaching only the most common meaning may create some confusion, but instructional time is limited. It's not likely to spend the whole class time on ail meanings of suffixes.

Our wish to encourage 'sensible dictionary use' may interfere with other methodological concerns. Students are likely to be checking every word of a reading text in their dictionaries when they should be reading for general understanding. So overstress on reading for the dictionary can be a deterrent to both vocabulary development and reading enjoyment.

Even with limitations and difficulties, the plan is worth implementing.

\section{REFERENCES}

[1] Carter, Ronald. (1998).Vocabulary, Applied Linguistic Perspective. London \& New York: Routledge Press.

[2] Harries, Albert J. \&. Sipay, Edward R. (1990). How to Increase Reading Ability. New York and London: Longman.

[3] Harmer, Jeremy. (1991). The Practice of English Teaching. London \& New York: Longman.

[4] Nation, P. \& Coady, J. (1988). Vocabulary and reading. In R. Carter \& M. McCarthy (Eds.), Vocabulary and language teaching (pp. 97-110). London and New York: Longman.

[5] Nation, P. (1994). New Ways in Teaching Vocabulary. Alexandria, VA: TESOL.

[6] Silberstein, Sandra. (1994). Techniques and Resources in Teaching Reading. London: Oxford University Press. Sandra

[7] Silberstein \&. Barbara K. Dobson. (2002). Reader's Choice, 4th Edition. Michigan: University of Michigan Press.

[8] Yu Sumei \&.Li Huiqin. (1999). College English Focus Listening (6). Shanghai: Shanghai Foreign Language Education Press.

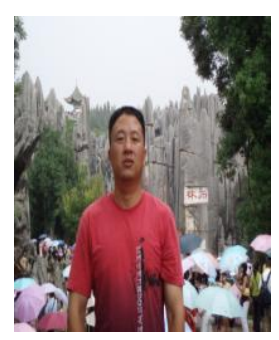

Mai Zhou was born in Ningxiang, China in 1970. He received his M.A. degree in linguistics from Central South University, China in 1998.

He is currently an associate professor in the School of Foreign Languages, Zhejiang Gongshang University, Hangzhou, China. His research interests include foreign language teaching and translation. 